Revista de la red interuniversitaria de estudios sobre las literaturas rioplatenses contemporáneas en Francia

6 | 2011

Juan José Saer. archivos, memoria, critica

\title{
Instantáneas de un movimiento
}

Florencia Amorena

\section{OpenEdition \\ Journals}

Edición electrónica

URL: http://journals.openedition.org/lirico/184

DOI: $10.4000 /$ lirico. 184

ISSN: 2262-8339

Editor

Réseau interuniversitaire d'étude des littératures contemporaines du Río de la Plata

Edición impresa

Fecha de publicación: 1 diciembre 2011

Paginación: 47-56

ISBN: 2-9525448-5-9

ISSN: 2263-2158

Referencia electrónica

Florencia Amorena, «Instantáneas de un movimiento », Cuadernos LIRICO [En línea], 6 | 2011,

Publicado el 01 julio 2012, consultado el 21 diciembre 2020. URL : http://journals.openedition.org/ lirico/184; DOI : https://doi.org/10.4000/lirico.184

\section{(ब) $\odot \Theta$}

Cuadernos LIRICO está distribuido bajo una Licencia Creative Commons Atribución-NoComercialSinDerivar 4.0 Internacional. 


\title{
INSTANTÁNEAS DE UN MOVIMIENTO
}

\author{
Florencia Amorena \\ Université Paris 8
}

uando Giles Deleuze ${ }^{1}$ analiza la imagen en su libro Imagen y movimiento llega a la siguiente conclusión: los elementos que la caracterizan nos enseñan que la imagen no sólo se puede ver sino que también se puede leer. Es legible tanto como visible. Con esta afirmación intenta mostrar que el acto de lectura va más allá de la mera grafía y que aceptando esta premisa es posible acceder a una comprensión más amplia de la imagen.

Pensar la imagen significa, en una primera instancia, la idea de percepción visual o más precisamente, de percepción trascendente. Como espectadores, observamos una imagen determinada. En cambio, en un texto, en tanto lectores, leemos un texto determinado. Deleuze intenta fusionar el ámbito de lo visible con el de lo legible, algo que de hecho ya había sido propuesto por los estudios de Peirce y de Barthes. Nuestro trabajo pretende indagar si es posible el camino inverso, es decir, tomar un texto "legible", para fundir en él "lo visible". Y si así fuese, ¿qué consecuencias implicaría esta fusión?

En este artículo, el deseo de buscar "lo visible" en "lo legible" tiene como antecedente el texto La grande ${ }^{2}$ de Juan José Saer. Como en otros trabajos suyos, en las largas descripciones de las distintas "escenas" representadas lo visual cobra importancia de manera tal que nos conducen a preguntarnos ¿cómo es posible ver estos textos?

Lo visual trae aparejado el problema de la percepción y por ende de tiempo y de espacio. Percibimos en un tiempo y espacio determinado. Y agregamos: tanto en el tiempo como en el espacio de la percepción

\footnotetext{
1 Giles Deleuze, La imagen-movimiento. Estudios sobre cine I, $2^{\mathrm{a}}$ ed., Buenos Aires, Paidós, 2007.

2 Juan José Saer, La grande, $1^{\text {a }}$ ed., Buenos Aires, Seix Barral, 2005.
} 
existe una noción de movimiento ya sea porque lo percibido o el que percibe está en movimiento, ya sea porque el tiempo sobre el cual se está percibiendo nunca se detiene.

Por otra parte ¿cuál es el vínculo entre lo "real” de dicha percepción y la literatura? Se ha discutido largamente la relación entre literatura y realidad. En cuanto a Saer, en no pocos trabajos se ha analizado el problema de narrar la percepción, el "papel" de la literatura, la "imposibilidad" de la escritura de dar cuenta de "lo real".

Alberto Giordano, frente a los interrogantes que plantea la relación literatura/realidad propone exceder la oposición entre realismo y autorrepresentación en la obra de Saer, es decir, superar el "efecto de real" barthesiano por un lado y el "efecto de literatura" por el otro-resultado de la autorrepresentación y de la puesta en evidencia de los procedimientos, observado en los trabajos de $S_{t e r n}{ }^{3}$ y Montaldo- ${ }^{4}$. Para este propósito, acuña un tercer término: el "efecto de irreal". Lo irreal, afirma, es "lo otro de la realidad, lo que para constituirse la realidad niega, enmascara, el vacío que es el corazón de nuestras evidencias, el enmascaramiento, afirmación de esa negación. Lo que aparece es que algo se oculta, lo que se afirma es que algo se niega, y ese algo incierto la literatura lo revela en su incertidumbre: ese algo no es nada, ni siquiera la nada. Las certezas se ven conmocionadas por la incertidumbre: "innombrable, lo real (lo irreal) es la presencia de la imposibilidad de un nombre, presencia que sólo se encuentra suspendiendo la confianza en el poder de nombrar." ${ }^{\prime 5}$

Partiendo de esta pequeña introducción nuestra propuesta intenta cuestionar una vez más el vínculo entre realidad y literatura desde la premisa que sostiene que "ver" el texto puede brindar otras respuestas. Con este fin, voy a detenerme en la narración de la imagen en La grande.

\section{Instantáneas saerianas}

En La grande el gesto de poder plasmar en el texto una imagen se relaciona con la idea de instantánea. En gran parte de los casos son

3 Mirta Stern, "El espacio intertextual en la narrativa de Juan José Saer: instancia productiva, referente y campo de teorización de la escritura", in Revista iberoamaericana, No 125, Pittsburg, octubre-diciembre 1983.

4 Graciela Montaldo, Juan José Saer. El limonero real, $1^{\text {a }}$ ed., Buenos Aires, Librería Hachette, 1986.

5 Ibid.p. 18 
imágenes que dependen de un azar, como si no hubieran sido planeadas, como si pudiera tocarnos ver cualquier cosa. Lo podemos ver en el club de pesca cuando los gestos de Escalante se describen a partir de planos detalles, pero sobre todo en las páginas que describen la caminata en busca de los moncholos. Cito un fragmento:

Extiende la mano para que Nula le pase la linterna. Los movimientos rápidos, el cambio de mano y de dirección hacen que el círculo de luz blanca ilumine al azar, en un desorden fugaz, diferentes fragmentos de cosas alejadas o próximas, de árboles, de lluvia oblicua y grisácea, de tierra, de río y de sus propios cuerpos, momentos inconexos del espacio y del tiempo flotando en la negrura, que a Nula le parecen constituir una versión más correcta del mundo empírico que, en la somnolencia diurna en la que los mantiene la tiranía de lo razonable, los hombres se han habituado a considerar con la doble superstición de la coherencia y de la continuidad. (p. 58)

Sin pose, sin pensarlo demasiado. Las escenas no tienen información crucial para el desvelamiento de los "enigmas" que sugiere el texto, son "momentos" elegidos al azar que unidos hacen avanzar el relato.

La instantánea sólo dura un instante, lleva en sí misma la idea de espontaneidad: es algo que no está planificado. Si la linterna ilumina los moncholos, entonces se narran los moncholos. Si ilumina la mano de Nula, será su mano la narrada. Los instantes atrapados dan cuenta de un "corte". Es decir, se entendería que hay una realidad X que implicaría una totalidad y que la percepción -la imagen- nos permitiría hacer un recorte de esa totalidad, tener de ella apenas algunos fragmentos.

Pensar en las instantáneas nos sirve para hacer de lo legible algo visible y, al mismo tiempo, hacer de esas imágenes algo legible, un lugar de reflexión sobre el tiempo y la percepción.

Con este movimiento se obtendría lo que quisiera llamar la "inteligencia": leer $\rightarrow$ ver $\rightarrow$ intelegere. Este último término se relaciona con la idea de "lo fijo". Fijar, como fija la instantánea, para dar sentido. Fijar el instante. Se podría pensar que cada escena es un punto y que esos puntos darían lugar al movimiento del texto. O, que una forma de concebir el movimiento en el texto (el movimiento en las imágenes del

6 "Intelego: to grasp or discern, recognize, distinguish mentally, to supply mentally something that is not expressed. Discerno: distinguish, separate, to show the difference in or between. to mark off, dividing boundary". Oxford Latin Dictionary, $28^{\mathrm{a}}$ ed., New York, Oxford University Press, 2004, 
texto) es a través de la fijación de estas escenas aleatorias. Para llegar a leer, ver y conocer "lo real" hay que fijar instantáneas, hay que cortarlas en el tiempo y discernirlas en él. Ahora bien, este procedimiento no me permite tener una noción más acertada del tiempo ni del movimiento sino una recomposición artificial de estos conceptos. Bergson considera que los momentos y las posiciones del tiempo son como instantáneas tomadas por nuestro entendimiento sobre la continuidad del movimiento y de la duración, dos términos que él implementa para dar cuenta de ese tiempo que es movimiento continuo, indivisible, porque siempre está en constante devenir, y duración porque está siempre siendo, siempre haciéndose, es una idea de sustancia que se mueve, que no se puede pensar como una línea sino como una simultaneidad del tiempo donde se unen pasado, recuerdo, posibilidad, etc. De esta forma, volviendo a La grande, con estas imágenes yuxtapuestas tendríamos apenas una sucesión práctica del tiempo y del movimiento que se pliega a las exigencias del lenguaje esperando que se predispongan al cálculo. Pero el tiempo y el movimiento, como explicaba Bergson, son otra cosa. ${ }^{7}$ Lo mismo parece querer decirnos La grande. Vamos a ver cómo la construcción de la imagen y su vínculo con el tiempo va más allá de querer mostrar una imposibilidad, una mera construcción artificial. La ambición es lograr demostrar que el texto es visible además de legible, que habla, más que de lo que hay, de eso que está detrás (lo que sería, para el filósofo francés, la intuición).

\section{Intuyendo el instante}

Hay un puente entre instante e intuición. En primer lugar, desde la etimología: uno y otra tienen que ver con lo inmediato, lo súbito. Si partimos de la definición de base de la intuición comprobamos que se trata de "la facultad de comprender las cosas instantáneamente". Es un golpe repentino que aparece sin que lo esperemos, un golpe de entendimiento que, como un rayo sorprendente y salido de la nada, ilumina lo que antes estaba en la oscuridad, desconocido (como la linterna o como las imágenes que aparecen y desaparecen fugazmente en el espejo retrovisor de $\left.\mathrm{Nula}^{9}\right)$.

7 Henri Bergson, La pensée et le mouvant, $16^{\mathrm{a}}$ ed., Paris, Presses Universitaires de France, 2009 , p. 7

8 Academia Española, Diccionario de la lengua española, 22ª edición, Madrid, Real Academia Española, 2001.

9 "El complejo de luz y de color asentado en medio del campo queda atrás, reaparece, 
Bergson ${ }^{10}$, en sus trabajos sobre la intuición filosófica, habla de ella como l'image intermédiaire -imagen intermediaria- entre la simplicidad de la intuición concreta y la complejidad de las abstracciones que la traducen, imagen que huye y se desvanece, que acosa (l'image qui hante) al espíritu del filósofo, lo sigue como si fuera su sombra a través de los cruces y desvíos del pensamiento y que, si no es la intuición misma, se le acerca bastante; bastante más, al menos, que la expresión conceptual, necesariamente simbólica.

¿Cómo es esta imagen? En primer lugar lo que la caracteriza es la ferza de negación ${ }^{l l}$ que hay en ella. Se comporta, nos dice Bergson, como el demonio de Sócrates en la vida práctica: prohíbe. Ante las ideas en general aceptadas, las tesis que parecen evidentes, la intuición insiste: "imposible". Imposible aunque los hechos y las razones nos están invitando a creer que aquello es posible, real, certero. La fuerza negativa que tiene esta intuición es singular, potente. La intuición es una ruptura en el orden de las representaciones simbólicas en el que nos movemos constantemente. De esta forma, el acceso a la positividad de la intuición reposa en un acto negativo, la duda, la sospecha. La intuición en sí es pura positividad, pero su punto de partida siempre es un quiebre con lo hábitos de la vida cotidiana, es siempre negativo. Así, en la doctrina del filósofo si bien lo que afirma puede variar hay algo que es definitivo: lo que niega. Esta es la manera en que, para Bergson, debe avanzar el pensamiento filosófico, dejándose llevar hacia las consecuencias de una lógica específica (cada filósofo seguirá el curso de su propio pensamiento), descubriendo, también, que enfrente de su propia afirmación, él va a experimentar el mismo sentimiento de imposibilidad que tuvo ante las afirmaciones de otros. Priorizando el movimiento de la búsqueda marcado por la intuición, el filósofo logrará

fragmentario, durante unos segundos, en el retrovisor, y al fin se borra por completo". La grande, ibid, p. 65.

${ }^{10}$ Henri Bergson, “L'intuition philosophique ”, in op. cit., pp. 117-142.

${ }^{11}$ Esta fuerza de la negación, además de llevarme a la idea de Nula, de pensar que estamos más cerca del mundo cuando asumimos que no es un todo continuo y coherente, me recuerda a la idea de literatura mencionada por Piglia en sus Formas breves: ¿Cuál es el problema mayor del arte de Macedonio? Las relaciones del pensamiento con la literatura, el pensar, diría Macedonio, es algo que se puede narrar como se narra un viaje o una historia de amor pero no del mismo modo. Le parece posible que en una novela puedan expresarse pensamientos tan difíciles y de forma tan abstracta como en una obra filosófica, pero a condición de que parezcan falsos. "Esa ilusión de falsedad”, dijo Renzi, "es la literatura misma". Ricardo Piglia, Formas breves, Buenos Aires, $1^{a}$ ed., Buenos Aires, Temas grupo editorial, 1999, p. 40. 
cuestionar hasta su propio sistema lógico; sólo volverá a él cuando vuelva a la intuición. De estas idas y vueltas se hará su doctrina, que está en continuo desarrollo.

Así, para alcanzar el fondo del espíritu (acaso "lo real", lo que está por debajo de la superficie, de la doctrina) es necesario salir de lo inteligible y, como la "inteligencia" opera en el tiempo, es necesario salir de la noción de tiempo que compartimenta, diseca y, por ende, no hace otra cosa más que alejarse de lo real. Para alcanzar la intuición hay que trabajar sobre la duración que se opone radicalmente al tiempo intelectual, aquel que es construcción artificial, doctrina. La duración ya no es yuxtaposición sino sucesión ininterrumpida del pasado en el presente que se encabalga en el avenir. En lugar de estados contiguos, en lugar de instantes que se acoplan, hay una continuidad indivisible y por lo tanto substancial. Intuición significa también conciencia, conciencia inmediata, visión que se distingue apenas del objeto visto, conocimiento que es al mismo tiempo contacto y coincidencia. ${ }^{22}$ Se trata de la conciencia agrandada, presionando sobre el borde del inconsciente que cede y que resiste, que se rinde y vuelve a tomar posición a través de alternancias rápidas de oscuridad y de luz. En La grande cuando Nula está en el supermercado reflexiona sobre la conciencia y su vínculo con las imágenes:

Nula pasea su mirada extrañada y atenta por el espacio iluminado, diciéndose:

Parece el lugar claro de la conciencia por el que transcurren los pensamientos. Hasta la música ambiental da la impresión de haberse detenido: su omnipresencia desaparece fundiéndose en el conjunto, y aunque para transcurrir necesita movimiento, cambio, tiempo, su conformismo rutinario hecho de desenvolvimientos previsibles y de melodías semejantes a tantas otras, parecen detenerla en un atascamiento sonoro que le impide avanzar. Es como el núcleo fijo de un átomo del devenir. Y después con imágenes que se aceleran y se entrechocan, algo que puesto en palabras daría más o menos lo siguiente: A la inversa, la parte clara de la mente se parece a este fragmento de lo exterior. Es como una pecera; por la parte superior, iluminada, se deslizan sin ruido los pescaditos de colores que se exhiben rápido y desaparecen, aunque algunos, insistentes y brillantes, vuelvan de tanto en tanto; pero más abajo, entre las plantas y las piedras recubiertas de musgo, el agua es cada vez menos transparente, oscurecida por sedimentos arcaicos acumulados en el fondo, donde se mueven una sombras confusas y sinforma reconocible,

\footnotetext{
${ }^{12}$ Real Academia Española, op.cit.
} 
sacudiéndose a veces con tanta violencia, que el agua se enturbia hasta arriba, a causa de los sedimentos en suspensión que se agitan con furia; entre la zona clara y la oscura, entre la franja brillante y familiar y el fondo inestable y fangoso, no hay línea de demarcación sino una frontera incierta, lábil, donde se entremezclan y conviven las dos franjas a la vez, modificándose mutuamente. (pp. 150-151)

Se sabe que la duración, el movimiento constante está, pero cuando se trata de la conciencia parecería que tendemos a fijar: son los pescaditos que podemos observar que aparecen ante nosotros, mientras que lo que está detrás, aquello que no podemos aprehender del todo está por debajo de la superficie, las sombras confusas que se mueven. Ambos existen, superficie y fondo, nosotros, en busca de "clarificar", detenemos el movimiento y observamos la superficie. Como la música que, de tanto repetirse, aparece como algo fijo, "un núcleo fijo del átomo del devenir"; la rutina la hace parecer inmóvil mientras que no es sino movimiento. En cambio, el fondo de la pecera, lo otro, lo que está por debajo de la superficie, oscuro, no se deja fijar, no se deja atrapar, moviéndose constantemente en formas que ni siquiera podemos reconocer: son sombras, son súbitas, son inasibles.

La intuición es la duración, el cambio puro. Nos acercaríamos a ella cuando nos acercamos al fondo de la pecera, cuando tomamos conciencia de que existe pero no podemos reconocer de qué está hecho, se trata de un continuo avanzar sobre un terreno de sombras inaprensibles. Para la intuición lo esencial es el cambio, no es la percepción en sí del objeto, ni su puesta en lenguaje ni su pensamiento. Todas estas ideas nos ponen frente al objeto en tanto inmóvil e invariable. Recordemos, se opone a la "inteligencia" que es discernimiento, que parte de lo inmóvil, que fija, que se da sobre todo en lo estable, en la "estabilidad de las cosas". ¿Cómo -se pregunta Bergson-alejarnos de esta idea tan arraigada en nosotros que busca fijar a partir de categorías, definiciones, doctrinas, para acercarnos a una idea de cambio y movimiento que se dirija a la esencia misma de las cosas? A través de la intuición en tanto movimiento y cambio constante.

Ante la pregunta inicial acerca de ver el texto en La grande, ¿cómo poder acercarnos a las imágenes narradas sin entrar en la disecación de los instantes sin fijarlos? Ciertamente la idea de instantánea sirve para pensar en la construcción de la imagen pero no es suficiente. Observamos que es un corte artificial. Es ruptura, no nos acerca a ese vínculo que intentamos descubrir entre literatura y realidad. Hay detención. 
La literatura no es una serie de puntos que se unen para mostrar algo. No es una recopilación o enumeración de procedimientos que sólo nos mostrarían la imposibilidad de "captar" su esencia. Sin embargo, estas instantáneas están ahí y bien podrían ser el punto de partida para pensar que la imagen en la literatura se vincula con la posibilidad infinita. Posibilidad dada a partir de la intuición que siempre está buscando afirmar a partir de una negación primera. Afirmación que no puede nombrar pero que está ahí. Posibilidad que, como la intuición, se trata de una forma de acceder al conocimiento que no puede ser ni percepción pura ni abstracción matemática ni sólo lenguaje sino constante devenir, imperceptible devenir. Este movimiento imperceptible es el de la duración.

Nuestra propuesta de lectura es que en esa "narración de la imagen", en esa "visualización del texto" se articula un vínculo entre literatura y realidad, un vínculo que está lejos de cristalizarse en definiciones o procedimientos. Habiendo derrotado, junto con Bergson, la idea de totalidad fija, y con ella la de reconstrucción de la misma a través de pedazos sueltos, sabemos que dicho vinculo no se dará a partir de la presentación de "fotos" tomadas al azar, planos construidos uno tras otro.

Barthes ${ }^{13}$ al marcar las diferencias entre la imagen fílmica y la imagen fotográfica encuentra que la primera no tiene un sentido de totalidad porque es empujada constantemente hacia otra foto: el referente se desliza, no se reivindica a favor de la realidad ni se queja de su antigua existencia. Como en el mundo "real", dice Barthes, el mundo fílmico se sostiene a partir de la presunción de que la experiencia continuará deslizándose, mientras que la fotografía no tiene avenir; inmóvil, presenta y retiene. A partir del análisis barthesiano se puede distinguir dos nociones de imagen, una que es móvil y otra que es fija.

Algo de las dos está en la instantánea saeriana, donde hay una idea de lo móvil no tal como lo conocemos sino como ese demonio de Sócrates que nos lleva a buscar el fondo de la pecera, un movimiento que es el de la intuición misma, ese cambio permanente que descubrimos, el motor oculto que hace avanzar al texto de instantánea en instantánea. Se trata de una forma de representar el constante devenir, la duración bergsoniana. Se trata, más aún, de comprender que la "instantánea de un movimiento" busca dar cuenta de la relación conflictiva entre literatura y realidad en tanto convivencia de dos fuerzas opuestas, la instantánea que busca fijar y la duda que nos hace pasar de una a otra sin detenerse

${ }^{13}$ Roland Barthes, CEuvres complètes V, 2a ed., Paris, Seuil, 1995. 
jamás, un movimiento constante de creación que no niega ni rompe con lo anterior pero que tampoco diseca en categorías cerradas. No hay negación definitiva -aunque sí inicial- pero tampoco afirmación final porque, en todo caso, son dos caras de la misma moneda. Negar, asumir la nada, la falta de categorías es también afirmar. Hay una fuerza de la negación que hace avanzar más allá de la afirmación posible, hacia la creación constante de la duración. 


\section{Bibliografía}

Barthes, Roland, Euvres complètes V ,2ª ed., Paris, Seuil, 1995.

Deleuze, Giles, La imagen-movimiento. Estudios sobre cine I, $2^{\text {a }}$ ed., Buenos Aires, Paidós, 2007.

Montaldo, Mirta, Juan José Saer. El limonero real, $1^{\mathrm{a}}$ ed., Buenos Aires, Librería Hachette, 1986.

Piglia, Ricardo, Formas breves, Buenos Aires, $1^{\text {a }}$ ed., Buenos Aires, Temas grupo editorial, 1999.

STERn, Mirta, "El espacio intertextual en la narrativa de Juan José Saer: instancia productiva, referente y campo de teorización de la escritura", in Revista iberoamaericana, № 125, Pittsburg, octubre-diciembre 1983. 